\title{
ANÁLISE DAS HABILIDADES DE CONSCIÊNCIA FONOLÓGICA EM CRIANÇAS DE 2ª SÉRIE ALFABETIZADAS EM DIFERENTES METODOLOGIAS DE ENSINO
}

\section{Analysis of phonological abilities awareness of second school children who became literate by different learning methodologies}

\author{
Viviane Breda dos Santos ${ }^{(1)}$, Vanessa Ferreira Horta ${ }^{(2)}$, Carina Corrêa Lacerda ${ }^{(3)}$, Kátia Nemr $^{(4)}$
}

\begin{abstract}
RESUMO
Objetivo: avaliar e analisar o desempenho em tarefas de habilidades fonológicas de crianças que cursam a $2^{\text {a }}$ série do Ensino Fundamental de escolas da rede privada do Estado de São Paulo, que estejam inseridas nos métodos de alfabetização: Montessoriano e Construtivista. Métodos: para a realização desta pesquisa foram selecionadas 60 crianças que cursam a ${ }^{2}{ }^{a}$ série do Ensino Fundamental de escolas da rede privada do Estado de São Paulo, sendo que estes alunos foram subdivididos, considerando o método de alfabetização: montessoriano ou construtivista, totalizando 30 crianças inseridas em cada metodologia de ensino. Foi aplicado o teste de Consciência Fonológica, por meio do Confias (Consciência Fonológicas: Instrumento de Avaliação Seqüencial) nas crianças selecionadas para a pesquisa, a aplicação do teste ocorreu dentro das escolas participantes, após prévia autorização dos pais. Resultados: as crianças não apresentaram diferença no desempenho em nível de sílaba e fonema em ambas metodologias de ensino. Conclusão: não foi possível evidenciar influência direta da metodologia de ensino no desempenho das tarefas de habilidades fonológicas.
\end{abstract}

DESCRITORES: Aprendizagem; Criança; Consciência; Educação

\section{INTRODUÇÃO}

A consciência fonológica ou metafonologia é uma habilidade metalingüística que se refere à representação consciente das propriedades fonológicas e das unidades constituintes da fala, inclusive a capacidade de refletir sobre os sons da fala e sua organização na formação de palavras ${ }^{1}$.

Pode ser definida como a capacidade de compreender a maneira pela qual a linguagem oral

(1) Fonoaudióloga Voluntária do Grupo de Linguagem e Aprendizagem da Faculdade de Medicina ABC; Fonoaudióloga da Clinica de Psicologia e Fonoaudiologia Psicoblue; Especialista em Linguagem.

(2) Fonoaudióloga Coordenadora Voluntária do Grupo de Linguagem e Aprendizagem da Faculdade de Medicina ABC; Fonoaudióloga do ABC Núcleo de Terapia Multidisciplinar e Assistência Psicopedagógica; Especialista em Linguagem.

(3) Fonoaudióloga; Clínica de Fonoaudiologia Delgam; Especialista em Linguagem.

(4) Fonoaudióloga; Professora concursada da Universidade de São Paulo; Doutora em Psicologia Social pela Universidade de São Paulo. pode ser dividida em componentes cada vez menores: sentenças em palavras, palavras em sílabas e sílabas em fonemas ${ }^{2-4}$.

A consciência fonológica foi considerada como algo monolítico, homogêneo, ou seja, a criança tinha ou não. Não sendo esta uma variável única, binária, dicotômica, ou seja, esta habilidade possui uma estrutura hierárquica, que atua por meio de estágios, iniciando-se com a consciência de unidades mais globais até chegar à consciência plena dos segmentos fonêmicos da fala. A consciência fonológica demanda que a criança ignore o significado da palavra e passe a prestar atenção à estrutura fonológica da mesma ${ }^{1}$.

Observa-se que uma deficiência na manipulação destas habilidades de consciência fonológica, pode gerar dificuldade na aprendizagem das correspondências grafema-fonema ${ }^{5}$.

$\mathrm{Na}$ prática clínica observa-se que os testes de consciência fonológica são utilizados como instrumento, para somar dados na avaliação de pacientes que apresentam queixas de dificuldades escolares, isso ocorre independente da abor- 
dagem pedagógica que esses pacientes estejam inseridos.

A pesquisa aponta à introdução formal da criança no sistema alfabético, como sendo fator ou causa primordial para o desenvolvimento da consciência fonológica ${ }^{6}$.

Em contrapartida, outros estudos apontam ser a consciência fonológica um pré-requisito para a aprendizagem da leitura e escrita ${ }^{7,8}$.

Em torno dos sete anos de idade, há um crescente desenvolvimento desta consciência, coincidindo com 0 início da escolarização ${ }^{9}$. Muitos estudos comprovam que, quanto mais a criança for atenta à estrutura fonológica das palavras, antes do início da alfabetização, maior será o sucesso no aprendizado da leitura e escrita ${ }^{10,11}$. O método de alfabetização é considerado outro facilitador que parece determinar as estratégias para a aprendizagem da leitura e escrita, além do nível de consciência fonológica ${ }^{9}$.

O modelo Montessoriano surgiu a partir de um sistema educacional desenvolvido por Maria Montessori que tinha como objetivo despertar um interesse espontâneo na criança, por meio da utilização de materiais didáticos multisensoriais, fornecidos em um ambiente propício à auto-educação. Nesta proposta de ensino o professor assume um papel de observador e incentivador dos fatores de aprendizagem, os professores não ensinam, mas ajudam a criança a aprender ${ }^{12}$.

O método multisensorial utilizado dentro desta metodologia pressupõe combinar diferentes modalidades sensoriais no ensino na linguagem escrita. Ao unir modalidades auditiva, visual, cinestésica e tátil estaria facilitando, desta forma, a leitura e a escrita ${ }^{13}$.

O modelo construtivista, baseado na teoria epistemológica de Jean Piaget, relata que existem quatro estágios de desenvolvimento cognitivo da criança, sendo eles estágio sensório-motor, estágio pré-operatório, estágio das operações concretas e estágios das operações formais ${ }^{14}$. Também refere que existem três pressupostos básicos: a continuidade das formas simbólicas, a neutralidade do domínio e as relações entre o conceptual e o simbólico ${ }^{15}$. Nessa visão do desenvolvimento do psiquismo humano o indivíduo é visto como um ser ativo que constrói conhecimentos, através de suas ações sobre o objeto. Para este conhecimento é necessário estar neurologicamente desenvolvido ${ }^{15}$.

Baseado nesta abordagem formou-se o modelo de escola construtivista que considera indispensável à aquisição do conhecimento uma interação entre a maturação, a experiência com o objeto e a auto-regulação. Pode-se dizer que o sujeito é ativo no processo de conhecimento e seleciona o que aprender e como fazê-lo; todo conhecimento parte de um conhecimento anterior; o conhecimento, ao ser adquirido pelo sujeito, é modificado por ele e, nessa transformação, podem ocorrer erros ou desvios que são construtivos, ajudando o sujeito a compreender melhor aquele conhecimento ${ }^{13}$.

Com base nos três pressupostos citados acima, a linguagem escrita é vista, na abordagem piagetiana, como um tipo mais complexo de atividade representativa, mas não diferente qualitativamente de outras formas de simbolização como, por exemplo, o desenho ou os gestos simbólicos ${ }^{13}$.

Esta postura levou os pesquisadores da abordagem construtivista a conceberem a leitura e a escrita como disciplinas escolares, e não como domínios específicos de desenvolvimento de cognição e linguagem ${ }^{13}$.

No modelo de ensino construtivista a aprendizagem escolar não pode ser vista como passiva, mas como um processo ativo de elaboração do aluno, além desta participação por parte do mesmo, o professor deve oferecer conteúdos que estejam ao alcance da capacidade cognitiva do aprendiz ${ }^{13}$.

Levando em consideração todos os aspectos citados acima, o objetivo do presente trabalho foi avaliar e analisar o desempenho em tarefas de habilidades fonológicas de crianças que cursam a segunda série do Ensino Fundamental de escolas da rede privada do Estado de São Paulo, que estejam inseridas nos seguintes métodos de alfabetização: Montessoriano e Construtivista.

\section{MÉTODOS}

Para a realização desta pesquisa foram selecionadas 60 crianças que cursam a $2^{\text {a }}$ série do Ensino Fundamental de escolas da rede privada do Estado de São Paulo, sendo que estes alunos foram subdivididos, considerando o método de alfabetização utilizado: Montessoriano e Construtivista, totalizando 30 crianças de cada método de alfabetização.

Foram definidos como critérios de exclusão crianças que estivessem ou tinham passado por atendimento fonoaudiológico, exceto casos de tratamento miofuncional exclusivamente, crianças que cursaram as séries anteriores (pré-escola e primeira série) em diferentes escolas e que apresentaram comprometimentos de natureza neurológica e/ou auditiva.

Para esta caracterização foi enviado um questionário de múltipla escolha aos pais destes alunos, contendo as seguintes perguntas:

- Nome e idade da criança;

- Cursou a pré-escola e a primeira série nesta escola atual; 
- Reprovou alguma série;

- Realizou atendimento fonoaudiológico;

- Por qual motivo;

- Esteve ou está em processo de alta;

- Apresenta algum comprometimento neurológico;

- Apresenta algum comprometimento auditivo;

Foi aplicado o teste de Consciência Fonológica, por meio do Confias (Consciência Fonológicas: Instrumento de Avaliação Seqüencial) ${ }^{1}$. Este teste apresentou 16 tarefas fonológicas, divididas em nível silábico e nível de fonema: síntese, segmentação, identificação de sílaba inicial, identificação de rima, produção de palavra com a sílaba dada, identificação de sílaba medial, produção de rima, exclusão, transposição, produção de palavra que inicie com o som dado, identificação de fonema inicial e final.

O teste foi aplicado durante sessões individuais de 20 minutos cada, na própria escola, em sala silenciosa apropriada, porém não tratada acusticamente.

A aplicação de cada tarefa foi precedida por dois exemplos iniciais em que o pesquisador explicou à criança o que deveria ser feito e, quando necessário, foram corrigidas as respostas. As ordens e explicações dadas às crianças para a execução de cada tarefa seguiram estritamente as recomendações dos autores.

Os resultados dos testes foram analisados, a partir das instruções dos autores, que previam a utilização do protocolo de respostas, nas quais as corretas valiam um ponto e as incorretas valiam zero. Na parte da sílaba, o máximo de pontos era 40 e na parte do fonema 30 , totalizando 70 pontos, o que corresponde $100 \%$ de acertos ${ }^{1}$.

O projeto de pesquisa foi avaliado e aprovado pelo Comitê de Ética e Pesquisa do CEFAC Saúde e Educação sob o n 92/06. Aos responsá- veis das crianças participantes desta pesquisa foi enviado o termo de consentimento livre e esclarecido, nos quais assinaram permitindo a realização da pesquisa.

Os resultados foram apresentados na forma de análise descritiva, com freqüências absolutas e relativas; na complementação da analise descritiva, foi usada a técnica de intervalo de confiança para média. A partir da pontuação final foi aplicado o teste estatístico não paramétrico de Mann Whitney correlacionando o número de acertos em ambos os grupos. Neste caso, foi considerado como valor de significância $p \leq 0.05$.

\section{RESULTADOS}

Observa-se na Tabela 1 o desempenho das crianças em relação à quantidade de números de acertos em nível de sílaba. Constatou-se que $69,6 \%$ das crianças inseridas na metodologia construtivista obtiveram o número máximo de quatro (4) acertos contra $80,0 \%$ das crianças da metodologia montessoriana. Analisando as respostas com três (3) acertos, verifica-se que a escola construtivista apresentou $16,7 \%$ e a escola montessoriana apresentou $15,6 \%$. Para as respostas com dois (2) acertos, as crianças da metodologia montessoriana obtiveram $15,6 \%$ e as construtivistas $10,0 \%$; já para as respostas com um (1) acerto, observa-se que 3,3\% das crianças eram da escola com abordagem montessoriana e $8,9 \%$ da abordagem construtivista.

Não foram avaliadas as seguintes quantidades de acertos: 0, 5, 6, 7 e 8, pois só havia uma resposta para cada uma dessas quantidades, dado este que torna este item irrelevante.

Observa-se na Tabela 2 o desempenho das crianças em relação à quantidade de números de acertos em nível de fonema. Constatou-se que

\section{Tabela 1 - Distribuição dos acertos quanto às medidas de tendências central Desempenho das Crianças Nível de Sílaba}

\begin{tabular}{|c|c|c|c|c|c|c|c|c|c|}
\hline & Nível Sílaba & Média & Mediana & $\begin{array}{l}\text { Desvio } \\
\text { Padrão }\end{array}$ & Quartil 1 & Quartil 3 & Tamanho & IC & p-valor \\
\hline \multirow{2}{*}{1 Acerto } & Construtivista & $8,9 \%$ & $3,3 \%$ & $9,6 \%$ & $3,3 \%$ & $11,7 \%$ & 3 & $10,9 \%$ & \multirow{2}{*}{0,197} \\
\hline & Montessoriana & $3,3 \%$ & $3,3 \%$ & $0,0 \%$ & $3,3 \%$ & $3,3 \%$ & 5 & $0,0 \%$ & \\
\hline \multirow{2}{*}{2 Acertos } & Construtivista & $10,0 \%$ & $10,0 \%$ & $5,4 \%$ & $8,3 \%$ & $11,7 \%$ & 4 & $5,3 \%$ & \multirow{2}{*}{0,435} \\
\hline & Montessoriana & $15,6 \%$ & $10,0 \%$ & $9,6 \%$ & $10,0 \%$ & $18,3 \%$ & 3 & $10,9 \%$ & \\
\hline \multirow{2}{*}{3 Acertos } & Construtivista & $16,7 \%$ & $16,7 \%$ & $12,3 \%$ & $6,7 \%$ & $23,3 \%$ & 7 & $9,1 \%$ & \multirow{2}{*}{1,000} \\
\hline & Montessoriana & $15,6 \%$ & $15,0 \%$ & $4,0 \%$ & $13,3 \%$ & $19,2 \%$ & 6 & $3,2 \%$ & \\
\hline \multirow{2}{*}{4 Acertos } & Construtivista & $69,6 \%$ & $70,0 \%$ & $32,7 \%$ & $60,0 \%$ & $96,7 \%$ & 9 & $21,4 \%$ & \multirow{2}{*}{0,735} \\
\hline & Montessoriana & $80,0 \%$ & $85,0 \%$ & $17,4 \%$ & $71,7 \%$ & $89,2 \%$ & 8 & $12,0 \%$ & \\
\hline
\end{tabular}

IC- intervalo de confiança

Teste Mann Whitney ( $p$-valores não significantes) 
Nível de Sílaba

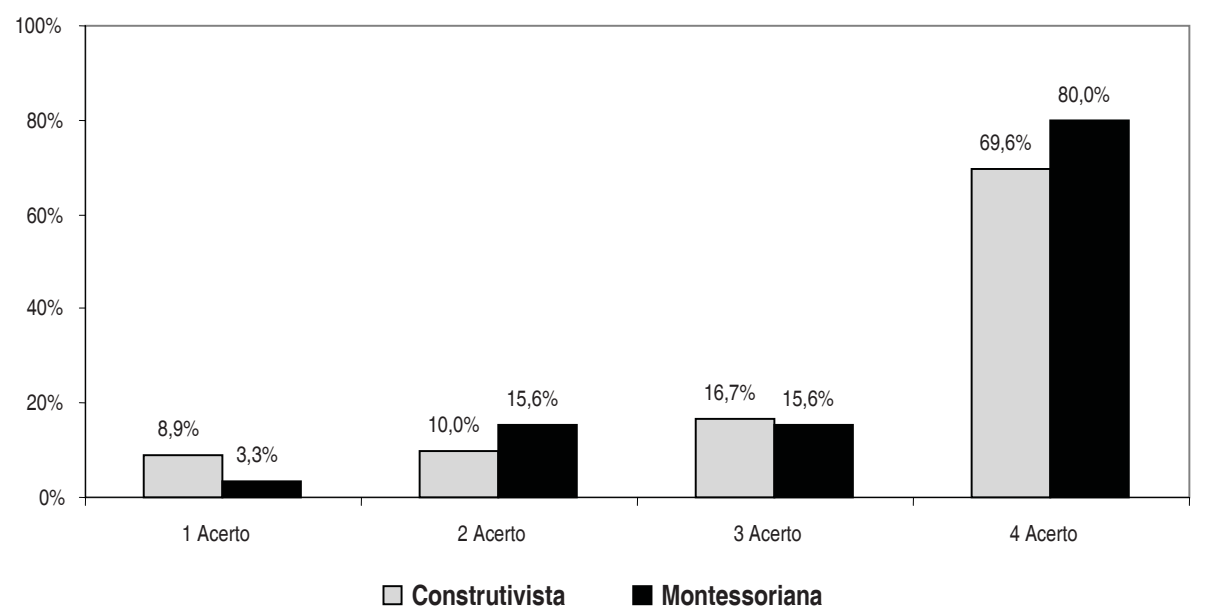

Figura 1 - Distribuição em percentuais quanto ao desempenho das Crianças no Nível de Sílaba em ambos os grupos

Tabela 2 - Distribuição das medidas de tendência central quanto ao desempenho das Crianças no Nível de Fonema em ambos os grupos

\begin{tabular}{|c|c|c|c|c|c|c|c|c|c|}
\hline & Nível Fonema & Média & Mediana & $\begin{array}{l}\text { Desvio } \\
\text { Padrão }\end{array}$ & Quartil 1 & Quartil 3 & Tamanho & IC & p-valor \\
\hline 0 Acertos & Construtivista & $29,2 \%$ & $21,7 \%$ & $31,1 \%$ & $5,8 \%$ & $45,0 \%$ & 4 & $30,5 \%$ & 1,000 \\
\hline \multirow{2}{*}{1 Acerto } & Construtivista & $17,3 \%$ & $20,0 \%$ & $8,6 \%$ & $10,0 \%$ & $23,3 \%$ & 5 & $7,6 \%$ & \multirow{2}{*}{0,387} \\
\hline & Montessoriana & $12,5 \%$ & $10,0 \%$ & $11,3 \%$ & $3,3 \%$ & $19,2 \%$ & 4 & $11,1 \%$ & \\
\hline 2 Acertos & Montessoriana & $10,0 \%$ & $8,3 \%$ & $4,7 \%$ & $6,7 \%$ & $11,7 \%$ & 4 & $4,6 \%$ & 0,210 \\
\hline \multirow{2}{*}{3 Acertos } & Construtivista & $23,9 \%$ & $23,3 \%$ & $11,2 \%$ & $16,7 \%$ & $30,0 \%$ & 6 & $9,0 \%$ & \multirow{2}{*}{0,886} \\
\hline & Montessoriana & $21,0 \%$ & $20,0 \%$ & $10,7 \%$ & $16,7 \%$ & $28,3 \%$ & 7 & $7,9 \%$ & \\
\hline \multirow{2}{*}{4 Acertos } & Construtivista & $26,7 \%$ & $20,0 \%$ & $22,9 \%$ & $8,3 \%$ & $43,3 \%$ & 7 & $16,9 \%$ & \multirow{2}{*}{0,063} \\
\hline & Montessoriana & $50,5 \%$ & $56,7 \%$ & $24,7 \%$ & $28,3 \%$ & $70,0 \%$ & 7 & $18,3 \%$ & \\
\hline
\end{tabular}

IC- intervalo de confiança

Teste Mann Whitney ( $p$-valores não significantes)

Nível de Fonema

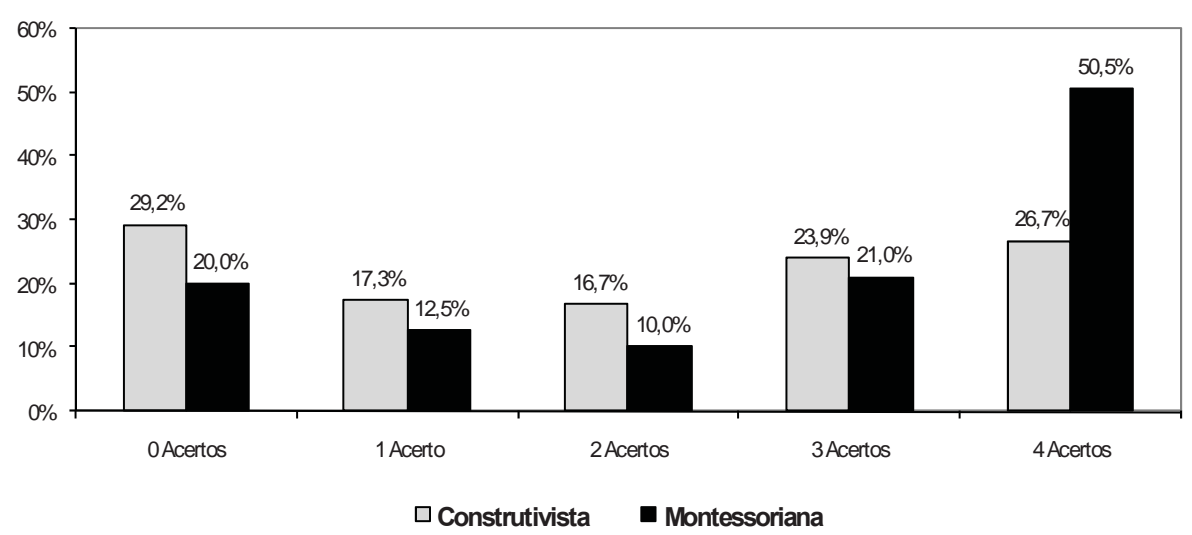

Figura 2 - Distribuição em percentuais quanto ao desempenho das Crianças no Nível de Fonema em ambos os grupos 
Tabela 3 - Distribuição em percentuais quanto ao desempenho das Crianças em Números de Acertos das Escolas Construtivistas no Nível Sílaba

\begin{tabular}{|c|c|c|c|c|c|c|c|c|c|}
\hline N. Acertos & S1 & S2 & S3 & S4 & S5 & S6 & S7 & S8 & S9 \\
\hline \multicolumn{10}{|l|}{0} \\
\hline 1 & & & & & & & $20,0 \%$ & $3,3 \%$ & $3,3 \%$ \\
\hline 2 & & & & $10,0 \%$ & & $3,3 \%$ & $16,7 \%$ & & $10,0 \%$ \\
\hline 3 & & & $10,0 \%$ & $20,0 \%$ & $3,3 \%$ & $36,7 \%$ & $26,6 \%$ & $3,3 \%$ & $16,7 \%$ \\
\hline 4 & $100,0 \%$ & $100,0 \%$ & $90,0 \%$ & $70,0 \%$ & $96,7 \%$ & $60,0 \%$ & $36,7 \%$ & $3,3 \%$ & $70,0 \%$ \\
\hline 5 & & & & & & & & $3,3 \%$ & \\
\hline 6 & & & & & & & & $20,0 \%$ & \\
\hline 7 & & & & & & & & $23,4 \%$ & \\
\hline 8 & & & & & & & & $43,4 \%$ & \\
\hline TOTAL & 30 & 30 & 30 & 30 & 30 & 30 & 30 & 30 & 30 \\
\hline
\end{tabular}

Legenda: S1 síntese, S2 segmentação, S3 identificação de sílaba inicial, S4 identificação de rima, S5 produção de palavra com sílaba dada, S6 identificação de sílaba medial, S7 produção de rima, S8 exclusão e S9 transposição.

Tabela 4 - Distribuição em percentuais quanto ao desempenho das Crianças em Números de Acertos das Escolas Construtivistas no Nível Fonema

\begin{tabular}{cccccccc}
\hline N. Acertos & F1 & F2 & F3 & F4 & F5 & F6 & F7 \\
\hline 0 & & & $6,7 \%$ & & $3,3 \%$ & $70,0 \%$ & $36,7 \%$ \\
1 & $6,7 \%$ & & & $10,0 \%$ & $26,7 \%$ & $20,0 \%$ & $23,3 \%$ \\
2 & $10,0 \%$ & $10,0 \%$ & $20,0 \%$ & $13,3 \%$ & $40,0 \%$ & $6,7 \%$ & $16,7 \%$ \\
3 & $30,0 \%$ & $30,0 \%$ & $40,0 \%$ & $16,7 \%$ & $10,0 \%$ & & $16,7 \%$ \\
4 & $53,3 \%$ & $60,0 \%$ & $33,3 \%$ & $10,0 \%$ & $20,0 \%$ & $3,3 \%$ & $6,6 \%$ \\
5 & & & & $26,7 \%$ & & & \\
6 & & & & $23,3 \%$ & & & 30 \\
\hline TOTAL & 30 & 30 & 30 & 30 & 30 & 30 \\
\hline
\end{tabular}

Legenda: F1 produção de palavra que inicia com o som dado, F2 identificação de fonema inicial, F3 identificação de fonema inicial, F4 exclusão, F5 síntese, F6 segmentação e F7 transposição.

Tabela 5 - Distribuição em percentuais quanto ao desempenho das Crianças Em Números de Acertos das Escolas Montessorianas no Nível Sílaba

\begin{tabular}{|c|c|c|c|c|c|c|c|c|c|}
\hline N. Acertos & S1 & S2 & S3 & S4 & S5 & S6 & S7 & S8 & S9 \\
\hline 0 & & & & & & & $3,3 \%$ & & \\
\hline 1 & & $3,3 \%$ & $3,3 \%$ & $3,3 \%$ & & & $3,3 \%$ & & $3,3 \%$ \\
\hline 2 & & & & & & $10,0 \%$ & $26,7 \%$ & & $10,0 \%$ \\
\hline 3 & & & $13,3 \%$ & $10,0 \%$ & $13,3 \%$ & $16,7 \%$ & $20,0 \%$ & & $20,0 \%$ \\
\hline 4 & $100,0 \%$ & $96,7 \%$ & $83,4 \%$ & $86,7 \%$ & $86,7 \%$ & $73,3 \%$ & $46,7 \%$ & & $66,7 \%$ \\
\hline 5 & & & & & & & & $3,3 \%$ & \\
\hline 6 & & & & & & & & $6,7 \%$ & \\
\hline 7 & & & & & & & & $33,3 \%$ & \\
\hline 8 & & & & & & & & $56,7 \%$ & \\
\hline TOTAL & 30 & 30 & 30 & 30 & 30 & 30 & 30 & 30 & 30 \\
\hline
\end{tabular}

Legenda: S1 síntese, S2 segmentação, S3 identificação de sílaba inicial, S4 identificação de rima, S5 produção de palavra com sílaba dada, S6 identificação de sílaba medial, S7 produção de rima, S8 exclusão e S9 transposição. 
Tabela 6 - Distribuição em percentuais quanto ao desempenho das crianças em números de acertos das Escolas Montessorianas no Nível Fonema

\begin{tabular}{cccccccc}
\hline $\mathbf{N}$. Acertos & $\mathbf{F 1}$ & $\mathbf{F 2}$ & $\mathbf{F 3}$ & $\mathbf{F 4}$ & $\mathbf{F 5}$ & $\mathbf{F 6}$ & $\mathbf{F 7}$ \\
\hline 0 & & & & & & $30,0 \%$ & $10,0 \%$ \\
1 & & & $3,3 \%$ & $3,3 \%$ & & $26,7 \%$ & $16,7 \%$ \\
2 & $6,7 \%$ & & $6,7 \%$ & & & $10,0 \%$ & $16,7 \%$ \\
3 & $20,0 \%$ & $20,0 \%$ & $33,3 \%$ & $3,3 \%$ & $33,3 \%$ & $13,3 \%$ & $23,3 \%$ \\
4 & $73,3 \%$ & $80,0 \%$ & $56,7 \%$ & $23,3 \%$ & $66,7 \%$ & $20,0 \%$ & $33,3 \%$ \\
5 & & & & $23,3 \%$ & & & \\
6 & & & & $46,8 \%$ & & & 30 \\
\hline TOTAL & 30 & 30 & 30 & 30 & 30 & 30 & 30 \\
\hline
\end{tabular}

Legenda: F1 produção de palavra que inicia com o som dado, F2 identificação de fonema inicial, F3 identificação de fonema inicial, F4 exclusão, F5 síntese, F6 segmentação e F7 transposição.

$50,5 \%$ das crianças inseridas na metodologia montessoriana obtiveram o número máximo de quatro (4) acertos contra $26,7 \%$ das crianças da metodologia construtivista. Analisando as respostas com três (3) acertos, verifica-se que a escola construtivista apresentou $23,9 \%$ e a escola montessoriana apresentou $21,0 \%$. Para as respostas com dois (2) acertos, as crianças da metodologia montessoriana obtiveram $10,0 \%$ e as construtivistas $16,7 \%$; já para as respostas com um (1) acerto, observa-se que $12,5 \%$ das crianças eram da abordagem montessoriana e $17,3 \%$ da abordagem construtivista. Podese observar que $29,2 \%$ das crianças inseridas na metodologia construtivistas erraram esse nível contra $20,0 \%$ das montessorianas.

Não foram avaliadas as seguintes quantidades de acertos: 5, 6, 7 e 8, pois só havia uma resposta para cada uma dessas quantidades.

Observa-se na Tabela 4 que as crianças da escola construtivista, obtiveram $70,0 \%$ de erros equivalentes a zero acerto e 3,3\% referentes a quatro acertos em relação à escola montessoriana que obteve $30,0 \%$ e $20,0 \%$ (Tabela 6 ) respectivamente, na realização da tarefa de segmentação (F6).

Observa-se na Tabela 4 que as crianças da escola construtivista, obtiveram $36,7 \%$ de erros equivalentes a zero acerto e $6,6 \%$ referentes a quatro acertos em relação à escola montessoriana que obteve $10,0 \%$ e $33,3 \%$ (Tabela 6 ) respectivamente, na realização da tarefa de transposição fonêmica (F7).

A análise estatística não identificou significância quanto ao número de acertos em ambos os grupos.

\section{DISCUSSÃO}

Os dados obtidos nos testes aplicados nos sujeitos no nível de sílaba mostraram que as crianças submetidas à abordagem de ensino construtivista apresentaram menor número de acertos em relação à montessoriana (Tabela1). Esses dados vão ao encontro com as pesquisas realizadas acerca deste tema, podendo verificar que a consciência silábica desenvolve-se antes da consciência fonêmica pelo fato da sílaba conter núcleo vocálico caracterizado por um pico de energia acústica que age como pista auditiva, facilitando a localização dos segmentos silábicos pelas crianças ${ }^{16}$.

Alguns autores relatam que o sub-teste de síntese silábica seria o de mais fácil execução, sendo o primeiro a ser adquirido por ser composto por sílabas, já que a sílaba é considerada a menor unidade natural de segmentação da fala ${ }^{17}$. Esta habilidade ocorre em idade pré-escolar que podem ser facilitadas pela natureza da língua portuguesa sendo adquirida antes da consciência do fonema ${ }^{18,19}$.

O mesmo ocorre na prova de segmentação silábica (S2), o que vai ao encontro com as pesquisas realizadas, que dizem que algumas tarefas de consciência fonológica são mais simples, exigindo apenas uma operação seguida de respostas, como a tarefa de segmentação de sílabas de uma palavra ${ }^{20}$.

Nas provas de identificação de sílaba inicial (S3), identificação de rima (S4), produção de palavra com a sílaba dada (S5), identificação de sílaba medial (S6), produção de rima (S7), exclusão (S8) e transposição silábica (S9), as crianças apresentaram desempenho inferior em relação às tarefas de (S1) e (S2), contudo sem diferença significativa entre as tarefas. Este achado pode ser justificado pelo fato de que as tarefas mais complexas exigem 
a realização de duas operações, ou seja, guardar a unidade na memória enquanto é feita uma nova manipulação. As respostas variam de acordo com o tipo de operação que é exigido pela criança ${ }^{20}$.

No nível de fonema as crianças das duas abordagens de ensino obtiveram desempenho também semelhante em todas as provas (Tabela 2), sendo estas: F1 (produção de palavra que inicia com o som dado), F2 (identificação de fonema inicial), F3 (identificação de fonema final), F4 (exclusão), F5 (síntese), F6 (segmentação) e F7 (transposição).

Pode-se notar que $26,7 \%$ das crianças das escolas construtivistas obtiveram a maior pontuação desse nível, contra $50,5 \%$ das crianças inseridas na metodologia montessoriana; $20,0 \%$ do total do mínimo dos números de acertos em relação a $29,2 \%$ das crianças da abordagem montessoriana (Tabela 2).

Observa-se como as crianças exercem um pior desempenho nas provas de nível fonêmico, comparado com o nível de sílabas; tal fato pode ser justificado desmembrando algumas das tarefas inseridas deste nível.

$\mathrm{Na}$ tarefa de exclusão fonêmica (F4), é necessário que a criança tenha alto grau de consciência fonológica e não pode ser realizado exclusivamente com pistas fonéticas, já que necessita da identificação e manipulação consciente do fonema a ser excluído em função de pronunciar o restante da palavra ${ }^{19}$; as crianças inseridas no ensino montessoriana obtiveram $46,8 \%$ de acertos (Tabela 6 ), desempenho melhor que as inseridas na abordagem construtivista sendo que esta apresentou $23,3 \%$ de acertos (Tabela 4).

$\mathrm{Na}$ tarefa de síntese fonêmica pode-se observar que esta é de alta complexidade, porque é necessário que a criança compreenda que as palavras são formadas por estruturas cada vez mínimas que podem ser segmentadas, aglutinadas, subtraídas, acrescentadas e recombinadas para posteriormente serem transcritas foneticamente ${ }^{21-23}$.

Pesquisas mostram que crianças que aprendem a ler devem resolver o problema de segmentação fonêmica, isto é, descobrir os elementos da fala contínua que correspondem aos elementos discretos da escrita alfabética. Estes elementos discretos, os fonemas, existem na fala, mas em nível abstrato e estão aglutinados e integrados em uma corrente contínua de som, existindo como unidades separadas somente na mente do falante ${ }^{18,19}$.

Mostrou-se neste estudo que nas tarefas de segmentação fonêmica (F6), houve melhor desempenho em crianças inseridas na metodologia montessoriana, sendo que os números de acertos chegam a $20,00 \%$ (Tabela 6) em comparação a construtivista que o total de acertos é de 3,33\% (Tabela 4).
Nesta tarefa $30,00 \%$ das crianças das escolas montessorianas não conseguiram realizá-la (Tabela 6), contra $70 \%$ da construtivista (Tabela 4).

$\mathrm{Na}$ tarefa de transposição fonêmica (F7), observa-se que crianças inseridas nas escolas montessorianas e construtivistas, obtiveram pior desempenho em relação a demais tarefas no nível de fonemas, entretanto observou-se que as crianças montessorianas demonstraram maior desempenho, sendo que $33,3 \%$ (Tabela 6) conseguiram o máximo da pontuação e 10,00\% apresentaram o mínimo de erros esperados para a tarefa; em comparação com as escolas construtivistas que obtiveram $36,7 \%$ de erros e $6,6 \%$ do total de acertos (Tabela 4).

Esse resultado pode ter ocorrido por esta tarefa ser a mais dependente da consciência fonêmica, uma vez que exige o isolamento e a manipulação de cada fonema da palavra para que a sua ordem possa ser modificada ${ }^{19}$.

As variáveis como experiência ambiental, escolar e talentos natos, fazem uma complexa contribuição para o desempenho das crianças em testes de consciência fonológica, e não devem ser considerados isoladamente ${ }^{23}$.

É importante ressaltar que em determinadas tarefas do teste de consciência fonológica as respostas das crianças da escola, cujo método de ensino é montessoriano apresentou um resultado diferenciado da escola construtivista. Porém, após a avaliação total dos resultados estatísticos do teste baseado nos acertos, não foi possível constatar diferença significativa no desempenho das crianças nas tarefas habilidades de consciência fonológica entre as escolas estudadas.

Levando em consideração as observações citadas acima, sugere-se a ampliação da amostra estudada para que sejam investigadas com maior profundidade a existência de significância, não constatada no presente estudo. Também, torna-se interessante pesquisar a forma utilizada pelas crianças para responder as provas do teste de consciência fonológica no nível fonêmico.

\section{CONCLUSÃO}

A partir dos dados encontrados nesta pesquisa, pode-se concluir que as crianças da segunda série do Ensino Fundamental alfabetizadas em escolas com metodologia de ensino Montessoriana e Construtivista da rede particular do estado de São Paulo, apresentaram resultados semelhantes no teste de consciência fonológica. Desta forma, não se evidenciou influência direta da metodologia de ensino no desempenho das tarefas de habilidades fonológicas. 


\section{ABSTRACT}

Purpose: to evaluate and analyze the performance in phonological ability tasks of second-grade children of the elementary school in private schools of the state of São Paulo, in the following methods of literacy: montessorian and constructivism. Methods: 60 second-grade children of in elementary school private schools of the state of São Paulo were select for carrying through this research, divided in schools inserted in the following methods: montessoriano and constructivism in a total of 30 children of each institution. Results: the children have not demonstrated difference in the performance in syllable level and phoneme in both education methodologies. Conclusion: it was not possible to evidence direct influence of education methodology on the performance of the tasks of phonological abilities.

KEYWORDS: Learning; Child; Conscience; Education

\section{REFERÊNCIAS}

1. Moojen S, Lamprecht R, Santos RM, Freitas GM, Brodacz R, Siqueira M, et al. CONFIAS Consciência fonológica instrumento de avaliação seqüencial. São Paulo: Casa do Psicólogo; 2003.

2. Santos MTM, Pereira LD. Teste de consciência fonológica. In: Pereira LD, Schochat E. Processamento auditivo central: manual de avaliação. São Paulo: Lovise; 1997. p. 187-95.

3. Alvarez A, Caetano A, Roman R. Diagnóstico e reabilitação da dislexia: uma visão neuropsicológica. Rev CEFAC. 1999; 1(2):96-106.

4. Capellini AS, Ciasca SM. Comparação do nível de leitura entre escolares sem e com queixa de dificuldade na leitura. Rev Soc Bras Fonoaudiol. 1999; 3(5):32-6.

5. Moraes J, Cary L, Alegria J, Bertelson P. Does awareness of speech as a sequence of phones arise spontaneously? Cognition. 1979; 7(4):323-31. 6. McGuiness D, McGuiness C, Donohue J. Phonological training and the alphabet principle: evidence for reciprocal causality. Read Res Q. 1995; 30(8):830-52.

7. Carraher TN, Rego LLB. O realismo nominal como obstáculo na aprendizagem da leitura. Cad Pesq. 1981; (39):3-10.

8. Rego LLB, Buarque LL. Consciência sintática, consciência fonológica e aquisição de regras ortográficas. Psicol Reflex Crit. 1997; 10:199-217.

9. Bradley L, Bryant PE. Categorizing sounds and learning to read: a causal connection. Nature. 1983; 301(3):419-21.

10. Roazzi A, Dowker A. Consciência fonológica, rima e aprendizagem da leitura. Psic Teor Pesq. 1989; 5(1):31-55.

11. Bigge ML. Teorias de aprendizagem para professores. São Paulo: Pedagógica Universitária; 1973. $45 \mathrm{p}$.
12. Capovilla AGS, Capovilla FC. Problemas de leitura e escrita. 4. ed. São Paulo: Memnon; 2004. p. 28-37.

13. Bezerra MCF. As visões de aprendizagem, desenvolvimento e linguagem existentes e suas implicações nos sentidos/significados atribuídos pela nossa cultura às dificuldades apresentadas pelas crianças em seu processo de aprendizagem/ desenvolvimento da linguagem escrita. Rev APG. 1996; 9:134-50.

14. Landsmann LT. Aprendizagem da língua escrita: processos evolutivos e implicações didáticas. São Paulo: Ática; 1995. 110 p.

15. Magnusson E. Consciência lingüística em crianças em desvios fonológicos. In: Yavas M. Desvios fonológicos em crianças: teoria, pesquisa e tratamento. Porto Alegre: Mercado Aberto; 1990. p. $109-48$.

16. Capovilla AGS, Capovilla FC. Efeitos da consciência fonológica em crianças com baixo nível sócioeconômico. Psicol Reflex Crit. 2000; 13(1):7-24.

17. Salles JF, Mota HB, Cechella C, Parente MAMP. Desenvolvimento da consciência fonológica de crianças de primeira e segunda séries. Pró-Fono. 1999; 11:68-76.

18. Santos MTM, Pereira LD. Teste de consciência fonológica. In: Santos MTM, Navas ALGP, Pereira LD. Estimulando a consciência fonológica. São Paulo: Lovise; 1999. p. 85-9.

19. Freitas GCM. Consciência fonológica: rimas e alterações no português brasileiro. Letras Hoje. 2003; 38(1):155-70.

20. Carvalho IAM, Alvarez RM. Aquisição da linguagem escrita: aspetos da consciência fonológica. Fono Atual. 2000; 4(11):28-31.

21. Shaywitz BA, Shaywitz SE, Pugh KR. Conatable RT, Skudlarski P, Fullbright RK, et al. Sex differences in the functional organization of the brain for lan- 
guage. Nature. 1995; 373(6515):607-9. Commented on Nature. 1995; 373(6515):561-2.

22. Morales MV, Mota MB, Keske-Soares M. Habilidades em consciência fonológica em crianças com desvios fonológicos. J Bras Fonoaudiol. 2002; 3(10):72-5.

23. Mann VA. Phonemeawareness and future reading ability. J Learn Disabil. 1993; 26:259-69.

RECEBIDO EM: 10/11/2006

ACEITO EM: 27/07/2007

Endereço para correspondência:

Rua Antonio Marcondes, 150

São Paulo - SP

CEP: 04267-020

Tel: (11) 69141867

E-mail: vi.breda@terra.com.br 